potentially represents an important collateral pathway, and we would therefore recommend its preservation.

This case report underlines the importance of being aware of collateral circulation in patients with aortoiliac occlusive disease undergoing coronary bypass surgery. Harvesting the ITA can cause acute limb ischemia in this subset of patients. Awareness of the potential collateral ITA-SEA-IEA pathway and the possible complications after ITA harvesting could avoid acute limb ischemia.

\section{References}

1. Barner HB, Standeven JW, Reese J. Twelve-year experience with internal mammary artery for coronary artery bypass. J Thorac Cardiovasc Surg. 1985;90:668-75.

2. LeRiche R. De la resection du Carrefour aortico-l'iliaque avec double sympathectomie lombaire pour thrombose arteritique de l'aorte: le syndrome de l'obliteration termino-aortique pour arterite. Presse Med. 1940;48:601-15.

3. Edwards EA, Lamay M. Occlusion patterns and collaterals in arteriosclerosis of the lower aorta and iliac arteries. Surgery. 1955;38:950-63.

4. Grollman JH. Winslow's pathway-it is not the only way. Catheter Cardiovasc Interv. 2000;49:445-6

5. Tsui SSL, Parry AJ, Large SR. Leg ischemia following bilateral internal thoracic artery and inferior epigastric artery harvesting. Eur J Cardiothorac Surg. 1995;9: 218-20.

\title{
Giant bronchogenic cyst within the aortic wall mimicking symptoms of acute type A aortic dissection
}

\author{
Ömer Senbaklavaci, MD, ${ }^{\mathrm{a}}$ Lars Oliver Conzelmann, MD, ${ }^{\mathrm{a}}$ Christoph Brochhausen, MD, ${ }^{\mathrm{b}}$ and
} Christian F. Vahl, MD, ${ }^{\mathrm{a}}$ Mainz, Germany

Bronchogenic cysts are the most common cystic lesions of the mediastinum. We report a patient who presented with chest pain and an aortic enlargement that was misdiagnosed as an acute type A dissection. Intraoperatively, this was

From the Department of Cardiothoracic and Vascular Surgery ${ }^{\mathrm{a}}$ and the Institute of Pathology, ${ }^{\mathrm{b}}$ University Medical Center of the Johannes Gutenberg-University, Mainz, Germany.

Disclosures: Authors have nothing to disclose with regard to commercial support.

Received for publication May 26, 2010; revisions received Sept 4, 2010; accepted for publication Sept 17, 2010; available ahead of print Nov 8, 2010

Address for reprints: Ömer Senbaklavaci, MD, Department of Cardiothoracic and Vascular Surgery, University Medical Center of the Johannes Gutenberg-University, Langenbeckstr. 1, 55131 Mainz, Germany (E-mail: senbak@hotmail.com).

J Thorac Cardiovasc Surg 2011;141:e7-8

$0022-5223 / \$ 36.00$

Copyright (c) 2011 by The American Association for Thoracic Surgery

doi:10.1016/j.jtcvs.2010.09.031 identified as a cystic lesion originating within the aortic wall. To our knowledge, this is the first reported case of a bronchogenic cyst within the aortic wall causing acute symptoms of an acute type A aortic dissection.

\section{CLINICAL SUMMARY}

A 35-year-old man was referred to our department for emergency operation after onset of acute chest pain and dyspnea. A computed tomographic scan (Figure 1) showed a $7.5 \times 7.5 \times 5.5-\mathrm{cm}$ ascending aorta with a $1-\mathrm{cm}$ pericardial effusion retrocardially accompanied by an echocardiogram demonstrating a grade II to III aortic regurgitation. In consideration of these findings and the acute symptoms of the patient, an intramural hematoma with a beginning type A dissection of the ascending aorta could not be excluded definitively.

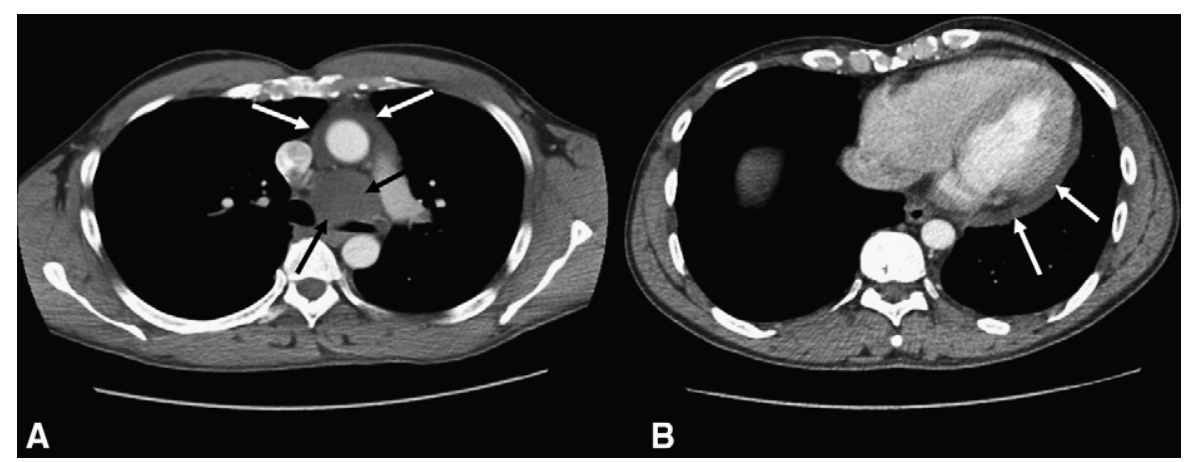

FIGURE 1. Computed tomographic images. A, White arrows show a thickening of the ascending aortic wall, a finding suggestive of intramural hematoma. Black arrows show a $7.5 \times 7.5 \times 5.5-\mathrm{cm}$ fluid lesion behind the ascending aorta with compression of the left main bronchus. B, Arrows show a 1 -cm pericardial effusion retrocardially. 


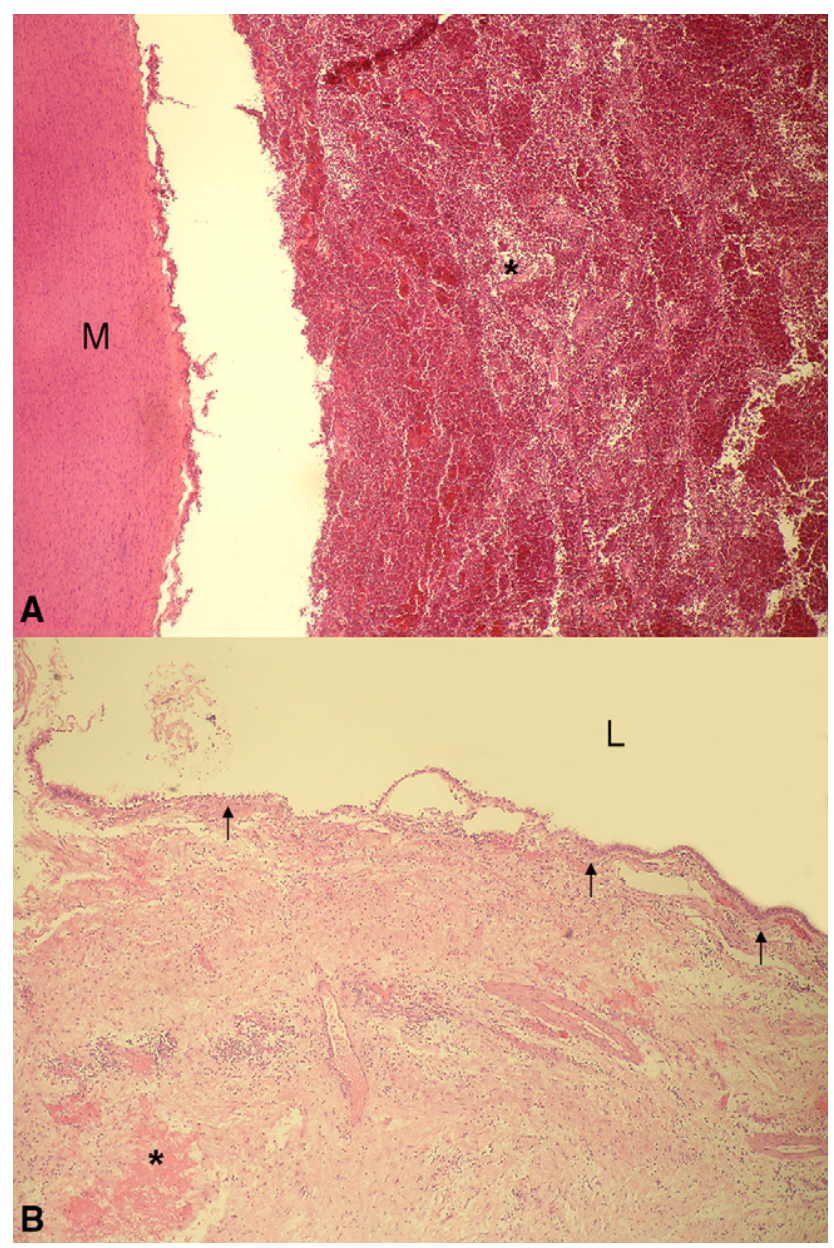

FIGURE 2. Histologic findings of the bronchogenic cyst, which was accompanied with bleeding in the adventitia of the aortic wall $(*)$, whereas the media $(M)$ of the aorta was intact. The bronchogenic cyst itself consisted of an epithelial lined (arrow) central lumina $(L)$ and had a connection to the adventitia of the aortic wall $(*)$. (Hematoxylin and eosin stain, original magnification $100 \times$.)

Intraoperatively, a large cystic lesion within the ascending aorta was found. The intima and media of the aorta were intact. The cyst originated between the media and adventitia, causing secondary compression of the left main stem, which explained the intraoperative ST-segment elevation and compression of the aortic valve and left atrium. The diseased ascending aorta was completely removed and replaced with a $26-\mathrm{mm}$ prosthesis. The aortic valve was reconstructed by means of inclusion of the leaflets into the prosthesis. The patient had an uncomplicated postoperative course and was discharged on the seventh postoperative day. Detailed histopathologic analysis confirmed the diagnosis of an intra-aortic bronchogenic cyst, which could be found within the adventitia of the aortic wall and was accompanied by bleeding within the adventitia and periaortic soft tissue (Figure 2). Six months' follow-up showed a $3 \times 3.5-\mathrm{cm}$ cyst infracarinally on magnetic resonance imaging without any complaint from the patient.

\section{DISCUSSION}

The bronchogenic cysts are believed to result from sequestration of cells from the region of the laryngotracheal groove during the fifth week of gestation. They occur mostly along the tracheobronchial tree and are usually found behind the carina. They account for $10 \%$ to $15 \%$ of all mediastinal masses. Bronchogenic cysts can be intrapulmonary or extrapulmonary and rarely show a communication with the airway. Maier divided their locations into 5 groups: paratracheal, carinal, hilar, paraesophageal, and miscellaneous. The fifth group, miscellaneous, includes abnormal locations, such as within the abdomen, ${ }^{1}$ within the diaphragm, ${ }^{2}$ in the presternal area, ${ }^{3}$ supraclavicular, ${ }^{4}$ and intrapericardial. ${ }^{5} \mathrm{~A}$ bronchogenic cyst within the aortic wall has not yet been reported as of our literature review. Although they are benign tumors, about half of all bronchogenic cysts become symptomatic because of compression of the airway or the esophagus or the presence of infection, indicating a surgical resection. In the present case there was an acute life-threatening situation caused by the risk for aortic rupture and aortic valve regurgitation, making an emergency operation necessary. Not only the morphology but also the symptoms mimicked an acute type A aortic dissection.

\section{References}

1. Coselli MP, de Ipolyi P, Bloss RS, Diaz RF, Fitzgerald JB. Bronchogenic cysts above and below the diaphragm: report of eight cases. Ann Thorac Surg. 1987; 44:491-4.

2. Buddington WT. Intradiaphragmatic cyst, ninth reported case. $N$ Engl J Med. 1957;257:613-5.

3. Magnussen JR, Thompson JN, Dickinson JT. Presternal bronchogenic cysts. Arch Otolaryngol. 1977;103:52-4.

4. Dubois P, Belanger R, Wellington JL. Bronchogenic cyst presenting as a supraclavicular mass. Can J Surg. 1981;24:530-1.

5. Gomes MN, Hufnagl CA. Intrapericardial bronchogenic cysts. Am J Cardiol. 1975;36:817-22. 